\title{
Turning hard problems on their heads ${ }^{1}$
}

\author{
DANIEL D. HUTTO \\ University of Hertfordshire, de Havilland Campus, Hatfield, AL10 9AB, England \\ (E-mail:d.d.hutto@herts.ac.uk)
}

\begin{abstract}
Much of the difficulty in assessing theories of consciousness stems from their advocates not supplying adequate or convincing characterisations of the phenomenon (or data) they hope to explain. Yet, to make any reasonable assessment this is precisely what is required, for it is not as if our 'pre-theoretical' intuitions are philosophically innocent. In what follows, I will attempt to reveal, using a recent debate between Chalmers and Dennett as a foil, why, in approaching this topic, we cannot characterise the data purely first-personally or third-personally nor, concomitantly, can we start such investigations using either first-personal or third-personal methods.
\end{abstract}

Key words: consciousness, first-person experience, hard problem, intersubjectivity, heterophenomenology

\section{Impossible problems}

How, in general, are the mental and the physical related? Where are experiences located? How are they unified in consciousness? Hard problems such as these and their cousins, the conceptual and epistemological problem of other minds, share the common feature of not having genuine solutions. These conceptual conundrums are not just 'hard'; they are impossible, or so I hope to show. Consider that the most lasting formulation of the hard problem of consciousness is cast as a problem about intelligibility, even though Chalmers, who coined the label, presents it as a problem about explanation. At bottom it asks, can consciousness be made intelligible in terms of something else, such as purely functional or physical categories?

Clearly, the most straightforward way of addressing this question would be to develop an explanatory theory of consciousness, one that, as many hope, might be ultimately incorporated, without residue, into a yet more fundamental theory or theories. As is well known, such theories of consciousness have been advanced from a variety of angles, including: the neurobiological (Crick 1994; Churchland 1989), the quantum mechanical (Penrose 1994), the functional (Dennett 1991; Lycan 1996) and the representational (Dretske 1995; Tye 1996). Bickle puts his finger on the rationale for these offerings in the preface to his book, Psychoneural Reduction. He spells out the crucial background assumption as follows, "The question of how psychological theories relate to neuroscience is no different from, e.g. the question of how theories 
in chemistry relate to their counterparts in physics. The object-level theories are different, and maybe the relationship between the levels is different, but the question at issue is the same" (Bickle 1998, p. x.).

I think this assumption is misguided and have elsewhere argued at length that the problem of understanding consciousness, like the problems encountered in trying to understand the denizens of the quantum realm, is such that in both cases the 'subject matter' cannot be modelled on anything that relates in our familiar 'object-based' schema. Doing so only generates philosophical confusion and nonsense ensues from typical attempts to address such confusion (Hutto 2000). For example, in the case of consciousness, once we are misled into speaking, inappropriately, of conscious 'properties' and 'states', we will feel the need to answer ill-posed questions about how these 'properties' and 'states' relate to their physical counterparts and we will begin to wonder about the location of consciousness and its phenomenal space and so on. To avoid such difficulties we realise that experiences are not objects, they are not experienced, but are the way in which we experience things.

But there is another serious problem with this sort of theoretical strategy. Given their conceptual nature, it is right to think that the only possible way to 'solve' hard problems would be to change the current rules of the game i.e. to fiddle with the concepts in question until the problems disappear. For instance, this is Humphrey's strategy in his recent attempt once and for all to put the mind-body problem to rest. He realises that this can only be achieved by recasting "the terms on each side of the mind-brain identity equation, phantasm, $p=$ brain state, $\mathrm{b}$, so as to make them look more like each other" (Humphreys 2000, p. 15). In praising his work Van Gulick observes that this general tactic is already quite familiar and that it "even has a name: Pat Churchland (1986) dubbed it 'co-evolution', reflecting the way in which our conceptions and theories on both sides of the divide change over time as we bring them into correspondence" (Van Gulick 2000, p. 94, see Hutto 2003, p. 205-216.).

Of course, this won't do if our concepts of experience are in no way theoretical or mediated by 'theory'. But there is no reason to suppose that even our sophisticated concepts of consciousness are speculative postulates. They are not the outgrowths of a primitive science about objects; rather they are outgrowths of primitive forms of response. For example, our colour concepts are tightly bound up with our way of experiencing things in basic cases, even if they are not restricted to them. Certainly, they are not open to revision and development in the way our concepts of atom and, say, carbon are. Given the way our experiences are related to their associated concepts, because they are fundamentally grounded in our nonconceptual way of being in the world, we can know in advance that unless our capacities for experience were to change radically, the hard metaphysical problem will not dissipate with the coming 
of hoped for 'theoretical' developments. Concepts of experience are just not on par with theoretical concepts of the 'physical' or 'chemical' variety.

Furthermore, even if theorising about consciousness were somehow shown to be appropriate, we would be getting ahead of ourselves by trying to engage in it prior to establishing clear target explanada. Much of the difficultly in assessing the multitude of new theories of consciousness is that the advocates of such theories do not supply adequate or convincing characterisations of the phenomenon (or data) they hope to explain. Yet, to make any reasonable assessment this is precisely what we need. In what follows, I will attempt to reveal, using a recent debate between Chalmers and Dennett as a foil, why, in approaching this topic, we cannot characterise the data purely firstpersonally or third-personally nor can we start such investigations using either first-personal or third-personal methods.

\section{False starts}

Seeking to make psychophysical relations 'generally' intelligible, as opposed to merely noting particular correlations for practical purposes, is not only a bad bet for rendering a satisfactory metaphysics of consciousness; if we make it our primary concern, it positively impedes the task of properly understanding the nature of experience. For example, Chalmers, who extols the virtues of producing a science of consciousness, presents matters in precisely the sort of way that fosters 'objectivist' assumptions. For him, the ultimate end of a science of consciousness is "to connect first-person data to third-person data; perhaps to explain the former in terms of the latter, or at least to come up with systematic theoretical connections between the two" (Chalmers, 1999 p. 8). In his view, ultimate success in this venture would culminate in a 'fundamental theory', which would explicate the simple, universal laws that underwrite the principles connecting experiences and information/brain processes.

Yet, despite his optimism about this sort of enterprise, he openly confesses that, as things stand, there are serious problems in characterising the firstperson half of the equation, given that we lack adequate languages/formalisms for characterising experience and robust methods for its investigation. He readily observes that, even in the branches of psychology and psychophysics, researchers still depend on "simple untutored introspection and verbal report" (Chalmers 1999, p. 10; cf. also 110). To address this, he speculates that in order for there to be a robust science of consciousness we must begin by augmenting existing and developing new and better methods for understanding it firstpersonally. He sees two ways forward; "perhaps we'll have to bootstrap our understanding of common elements of experience, or perhaps we'll be able to go further with some sort of building-block methodology" (Chalmers 1999, p. 11). Specifically, he proposes that we need to develop formalisms that 
better capture the 'structure of experience' and advance theories about its non-structural aspects.

Sticking with the first possibility, it is difficult to see what the development of a science of consciousness would amount to, other than, perhaps, discovering brute correlations between the occurrence of certain types of experience and their neural substrates. For, we might wonder, what would the development of our 'understanding of common elements of experience' consist in? Consider Chalmers' suggestion that colour experiences might be decomposed into other experiences, such as those of brightness, saturation and hue. Noting this complexity in the 'qualitative aspects of experiences' is hardly new - indeed, it is taken from the taxonomy we have for carving up colour experience using our general and quite robust, public categories. In this light, talk of 'decomposition' is nothing more than a crude reification of our abilities to make such distinctions. Seen in this light, the important question is, how could the recognition that we have such capacities possibly aid the development of a scientific account of the relation between first- and third-person aspects of experience, as opposed to merely giving us further, perhaps more detailed, correlations to explain?

Against this background, the bolder idea that we might develop an entirely fresh theory of the subjective aspects of consciousness might appear more promising, This is the other possibility that Chalmers considers, that we might develop a simple building-block theory of 'proto-qualia' that would reveal more of the internal composition of experiences. Yet again, this idea rests on a serious misunderstanding or mischaracterisation of the nature of our experiences, treating them as objects or entities that might be 'composed of' smaller units. That is to say, the idea that we might develop theories about 'proto-qualia' rests - at least implicitly - on treating experiences as if they were some kind of 'inner object'. Why, like so many others, is Chalmers inclined towards this sort of view? The following passage suggests an answer:

The clearest cases of direct phenomenal concepts arise when a subject attends to the quality of an experience and forms a concept wholly based on the attention to the quality, 'taking up' the quality into the concept. This sort of concept formation can occur with visual experiences, as in the Mary case, but it can equally occur with all sorts of other experiences: auditory and other perceptual experiences, bodily sensations, emotional experiences and so on. (Chalmers 2003, p. 235)

The reifying tendency is fostered by the idea that our ordinary expressions concerning experiences are best understood as a species of reportage and that we access our experiences by means of introspection, a capacity that operates in a way analogous to that of inspecting public objects by means of perception. All this is underlined by Chalmers' claim that experiences 'constitute' part of the content of our introspective reports. Indeed, following a long line of other analytic philosophers before him, he models conceptual content as if it 
were a complex physical arrangement of objects, even going so far as to claim that direct phenomenal concepts have 'slots' for their 'instantiated qualities' (Chalmers 2003, p. 243). Thus:

The content of a phenomenal concept and corresponding phenomenal belief is partly constituted by an underlying phenomenal quality, in that it will mirror the quality (picking out instances of the quality in all epistemic possibilities) ... (Chalmers 2003, p. 235, see also 233, 236-239).

Ironically, subjective reports turn out to be quite unlike mundane reports about objects of the more familiar sort. The main difference is that, being essentially 'first personal', there can be no independent standard against which to judge to what these concepts refer to or whether they do so successfully. Thus, in taking them seriously we must suppose that the reports about such experiences are incorrigible for it is quite clear that there could be no basis for challenging or questioning their accuracy; nor even any room for doubting that there is anything to report at all. This is indeed a price that Chalmers is willing to pay. He admits that a 'direct phenomenal belief cannot be false' and that his framework "supports an incorrigibility thesis" (Chalmers 2003, p. 241-242, see Dennett 2002, p. 15). Still, he limits its scope by distinguishing between 'direct' and 'standing' phenomenal concepts and beliefs, holding that the same incorrigibility does not extend to reports involving ordinary experiential concepts in general. Nevertheless, he is admirably clear about the commitments of such a position.

The view I have set out here is just the sort of view that Wittgenstein directed his private language argument against. The nature of the private language argument is contested, so in response I can say only that I have seen no reconstruction of it that provides a strong case against the view I have laid out. Some versions of the argument seem to fall prey to the mistake just outlined, that of requiring a strong sort of 'repeatability' (and an exceptionally strong sort at that, requiring the recognizability of correct repeated application). A certain sort of repeatability is required for concept possession, but it is merely the 'hypothetical repeatability' involved in present predictability of the concept to actual and hypothetical cases, with associated truth-conditions. (Chalmers 2003, p. 241).

Wittgenstein's rejection of the very idea of a private language as simply confused was, at its heart, a rejection of a possible move to secure the objectivity of the rules for the use of concepts. His criticism of the sort of view Chalmers promotes was not based on support for any kind of verificationism, as implied by talk of a commitment to a condition of strong repeatability. The objection goes much deeper, for Wittgenstein seeks to expose that the imagined private linguist is unable to establish any rule for use by simply 'attending' to an experience. Such an act would not suffice to establish a standard of any sort for even imagined concept use. This was the basis of Wittgenstein's rejection of the very idea that meaning could be fixed by ostensive definition 
(or by some purely causal means). Failing to see this often generates confusion about the focus of Wittgenstein's critique because it can appear that his worry is really only one about our capacity to apply concepts, hence leaving the possibility that such concepts might have truth predictable content untouched, as Chalmers supposes in the above quotation. If there is no possibility of establishing a standard at all, then there is simply no possibility of applying the concept correctly or incorrectly - even in a one-off or purely hypothetical use. As such, despite advertisements to the contrary, the worry remains that Chalmers' account of how a rule for the use of a concept is established - his account of concept acquisition - is at fault. Merely attending to the phenomenal quality in question does not establish "predictability, with assessibility for truth or falsehood" (Chalmers 2003, p. 240; see Hutto 1995, p. 467468).

Dennett rightly sees Chalmers' approach as nothing short of reviving the worst sort of 'mythology of mind'. In a paper entitled 'The Fantasy of FirstPerson Science', he lampoons its vision of the future. Returning to the title, he concludes the paper by saying, "First-person science of consciousness is a discipline with no methods, no data, no results, no future, no promise. It will remain a fantasy" (Dennett 2001, p. 8). Nevertheless, Dennett remains committed to the idea of developing a science of consious. Yet whereas Chalmers sees providing taxonomy of our pre-theoretical subjective experience as a necessary first step towards this goal, Dennett changes the rules by advocating a different, altogether more cautious, starting point. In Quinean fashion, we are told: "the primary data are the utterances, the raw, uninterpreted data. But before we get to theory, we can interpret these data, carrying us via (c) speech acts to (b) beliefs about experiences. These are the primary interpreted data, the pre-theoretical data, the quod erat explicatum (as organised into heterophenomenological worlds), for a science of consciousness" (Dennett 2003, p. 21).

With typical rhetorical panache, he asks, "Shouldn't our data include not just the subject's subjective beliefs about their experiences, but the experiences themselves?' (Dennett 2001, p. 3). 'No', he replies. He argues that, unless we start our inquiries by focusing explicitly and only on a subject's beliefs about experiences, we will be driven to accept precisely what we should not: (1) that experiences might be inaccessible to judgement and report - even from the first-person perspective, and (2) that subjects cannot be mistaken in their beliefs about their experiences. For the purposes of this short analysis, I will concentrate on Dennett's second point; the first will take care of itself in the course of my argument.

Dennett rightly insists, "There is no proposition about one's own or anybody else's conscious experience that is immune to error, unlikely as that error might be" (Dennett 2002, p. 13). Of course, we can be mistaken in our claims 
and beliefs about what we experience. He is quite right to emphasise that we cannot have incorrigible, infallible beliefs about anything; (as Davidson put it, 'error is what gives belief its point'). Over the years Dennett has campaigned hard against our standard intuitions on this score, devising a whole range of examples designed to get us to relinquish our confidence in our descriptions of what is going on in our experience. In his attack on Chalmers, he makes use of Ramachandran's experiment, involving motion capture under insoluminance. Subjects are presented with the illusion of a yellow blob covered in black dots, which is apparently moving. However, in fact it is only the black dots that move and not the yellow blob itself. The point is that subjects report seeing the yellow blob move, despite the fact that it does not. So what is the status of such reports? How do they depend on experiences? In characteristic style, Dennett torments his victim, by asking:

Do you see the motion? You see apparent motion. Does the yellow blob really move? The blob on the screen doesn't move. Ah, but does the subjective yellow blob in your experience move? Does it really move, or do you just judge that it moves? Well, it sure seems to move! That is what you judge, right? (Dennett 2001, p.4.)

The ontological moral he is inclined to draw from this case and many others like it is that although we ought to allow subjects to have the final word in saying how they judge that things appear to them, this in no way commits serious investigators to regarding their reports as indexing anything 'real', such as appearances or experiences. Indeed, he bids us to treat these as 'fictional items' that feature in longer or shorter narratives about what we putatively 'experience'. This is, of course, his famous heterophenomenological method and according to Dennett, "Heterophenomenology is nothing but good old 3rd person scientific method applied to the particular phenomena of human (and animal) consciousness" (Dennett 2001, p. 3). And, as he has even more recently put it, "This third-person methodology, dubbed heterophenomenology (phenomenology of another not oneself) is, I have claimed, the sound way to take the first-person point of view as seriously as it can be taken" (Dennett 2003, p. 19).

Ultimately he is attracted to a single-tiered form of strong inferentialism about belief and meaning which drives him to suppose that, in developing a third personal science of consciousness, it makes sense to tackle what he calls Turing's question, as formulated below:

How could we make a robot that had thoughts, that learned from 'experience' (interacting with the world) and used what it learned in the way we do? (Dennett 2001, p. 1).

The point is that to accept Dennett's purely third-personal methodology commits one to the idea that we would have no choice but to regard anything that reliably produced 'patterns of behaviour' that are identical to those you 
or I produce in making verbal utterances as conscious. Having endorsed this conclusion, it should be possible to explain the capacity for consciousness in terms of robots that decompose into yet smaller robots, and so on, until the groundfloor mechanisms are revealed and the mystery is dispelled. We are told:

I argue that if, for instance, $\mathrm{Cog}$, the humanoid robot being developed by Rodney Brooks and his colleagues at MIT, were ever to master English, its own declarations about its subjectivity would systematically trump the 'third-person' opinions of its makers, even though they would be armed, in the limit, with perfect information about the micro-mechanical implementation of that subjectivity (Dennett 2002, p. 14).

Brook's laboratory creation, Cog, or its final version, would then be an existence proof that robots can enjoy experiences. Given our technical ingenuity, I take it that, however far-fetched it might seem, it is really just a matter of time and patience before we get a robot of the sort that passes muster for these purposes. But why wait? Ex hypothesi, let us imagine an encounter with $\mathrm{Cog}$ in which we are fooled by its performance. For all intents and purposes, this would mean that it could navigate a conversation as well as you or I (but importantly, no better) and its behavioural repertoire would be impeccable, in that it could mimic not only our conversational virtues but also all our standard flaws and weaknesses as well. I conclude that this would only be a testament to the ingenuity of its builders. If I am right, even though a great deal might be learnt in the process of building such a robot, Cog would remain a work of art as opposed to a tool for understanding consciousness. At best, it could act as a kind of weathervane for detecting certain prevailing, as opposed to the correct, philosophical, intuitions.

Dennett (or his imagined successor) would claim this assessment is grossly unfair. What entitles me to talk of being 'fooled'? What more could be asked for? Am I not simply falling in line with those who complain that Dennett's heterophemonmenology leaves something out? Yes. Doesn't sharing this concern really only reveal something about $m y$ psychology; i.e. that I am in the grip of the 'zombie hunch'? Not quite. I do not worry at all about the possibility of 'physical' zombies that are molecule for molecule identical with ordinary folk (only supposedly they lack consciousness), for like Dennett I believe them to be nonsensical constructs. I do however think 'functional' zombies ought to terrorise us, or rather Dennett and his followers.

To see the problem in a good light, we must understand that, in endorsing his particular brand of conceptual inferentialism, Dennett has lost sight of the special role that the character of our experiences has to play in the nature of our experiences and the shaping of experiential concepts. In simply equating experiences with beliefs or reports, he is forced to identify the character of experience with nothing more than textual statements, the conceptual content 
of which is fixed entirely by the totality of their inferential relations. In doing so, he effectively confuses the add-on extras or higher-order supplements with the essential ingredients themselves, in this case of experiences.

To see the issues properly it is worth considering a key feature of the sensorimotor contingency approach to perceptual experience. Refreshingly, this approach openly rejects the very idea that experiences can be understood by means of the object-based schema. Its advocates stress that experiences are not objects of perception but that their character is bound up with 'the way in which we perceive ${ }^{2}$. In its mildest form, their central claim is that:

The experience associated with a modality exists only within the context of an acting organism, and with the context of other senses available to the organism ... vision, audition, touch and so on, will have their own specificities due to the particulars of the sensors and sensorimotor contingencies involved ... (O'Regan and Noë 2001 p. 959).

Although there are many aspects of the published version of this account which I reject, this much is fundamentally right (Hutto 2006a, 2006b). Yet, if we accept this, then worries about functional equivalence ought to rear their ugly heads when we try to better understand consciousness through robotic and AI research. For it has been granted from the outset that Cog will not be even remotely similar to a living human being in its make-up. It will presumably respond to the same 'objective' features of the world that you or I do, only by quite different means. Therefore given its alternative composition, its non-inferential links - those that matter most in determining the character of experience - will be alien to ours. Here, like so many functionalists before him, Dennett must face up to the fact that there is more than one way to skin a cat.

Recognising this, we ought to wonder what we will learn about consciousness by constructing elaborate robots. For even if we built one that mimics our interactions and responses in all respects, we will still be uncertain whether it has 'awareness' or if it has awareness in anything like the way we do. We already exhibit this sort of ambivalence when wondering about the conscious life of certain animals. For with them our reactions are very different from those we make so readily towards one another. Such hesitancy is not grounded in the fact that they fail to make the full wealth of sophisticated conceptual discriminations, as Dennett has implied at times (cf. Hutto 1995, p. 470472). Conceptual literacy is only one part of the story about experience; it is certainly not the essential one.

\section{The role of experience}

Like many others, Dennett sees limited possibilities. We can either opt for a first-personal or third-personal approach to consciousness. In avoiding the first 
path, he erroneously swings too far in the opposite direction and threatens to exclude that which he hopes to explain, experience itself. I want to challenge the idea that our options are so limited. For drawing on the idea that experience has a non-conceptual basis, it is possible to account for the sorts of errors to which Dennett shows we are prone, without endorsing the idea that we are incorrigible or infallible in our judgements about experience.

Dennett conflates matters by failing to recognise the different status of the claims, reports and judgements we make about things, those involving beliefs, and the roles played by talk of our experiences. This requires attending to the circumstances in which we introduce 'looks' talk. In many cases, such talk does not function in any way like the making of standard claims or reports. Rather, as in the case Dennett cites, such talk is usually associated with the withdrawal of a stronger claim, serving to explain why such a claim was mistaken. For we are not wrong in thinking that it appears as if the yellow blob is moving; that is just to say how things look to us. Hence, when confronted with our error, we retreat from the claim that the yellow blob was moving to the explanation that it looked as if the yellow blob was moving. But the reason that we cannot be wrong about this is not because we have incorrigible introspective access to our own experiences. It is rather that we are not making a claim at all; we are withdrawing one claim while explaining, at the same time, why we were inclined to make it in the first place. Consequently, on this view there is no need to treat such remarks as reports about fictional or inner objects or to focus only on judgements at the expense of explanations involving experiences.

On this analysis, our talk of how things appear to us is not open to challenge precisely because it serves as non-inferential justification for other judgements and beliefs (cf. Brandom 1994, p. 293-294). In order to preserve the vital distinction needed to make sense of the differences between experiences and the kinds of cognitive errors they help to explain, we must recognise that experiences should not be identified with purely conceptual dispositions to respond. To give articulate expression to 'the way things appear to us' is to speak of experiences; our linguistic expressions in such cases go proxy for our more primitive responses. This is why, as Brandom neatly puts it, "the distinction between appearance and reality does not apply to appearances" (Brandom 1994, p. 295). At this level we encounter 'justifiers' that cannot be justified. This is not to say they are 'unjustified' in a pejorative sense; it is rather that introducing talk about how things appear to us forms part of the very ground for justification. Without appeal to experiences we would be at a loss to explain why we come to form mistaken beliefs when we are subject to visual and other kinds of illusion. Thus, we cannot be as cautiously neutral about their existence or character as Dennett would like. 
It is also worth noting that, a fortiori, we cannot adopt the kind of global reserve Dennett advocates without reducing our 'reports' about experiences to mere noises. For, unless we take for granted that experiences form the basis of another's expressions or of their descriptions of how things appear to them, we will have no other means of getting to the second stage of preparing the data, that of interpreting "recorded verbal utterances which serve as our "raw data"” (cf. Dennett 2001, p. 2).

Still it is important to realise that Dennett's scruples are born from a fear of becoming ontologically committed to 'inner objects, states and events', which can only be accessed first-personally. He is right to think that, in order to be meaningful, our claims about experience cannot be directed at private items of experience. The very possibility of conceptual meaning, error and its assessment requires an inter-subjective space. This is precisely why claims about how things stand in the world are not on par with accounts of how things appear to us. But acknowledging this is no reason to deny the existence of experiences that lie at their heart. These are part and parcel of our primary engagements with others and with things and their features. It follows that our facility with such expressions is parasitic on the more basic literacy in making ordinary claims about public, worldly items, which in their turn depend on our more primary modes of experience

Looking at matters in this light allows us to treat experiences in what we might call a 'theoretically' innocent way, recognising their role in our lives and communal practices. I prefer not to speak of 'qualia' at all because the label itself tends to promote the 'name-object' view and the sort of tendency towards reification that is objectionable. This seemingly legitimises talk about 'inner states' and it is a short road from such talk to the host of other unpalatable philosophical commitments discussed earlier. However, I agree with Find that we will do well to specify, in some way, the 'pre-theoretic notion' that must be implicitly endorsed by all of those engaged in this debate. Like Flanagan, she proposes that we define qualia in the following way:

(Q) Qualia are the way things seem to us. (2001, p. 148-149; cf. Flanagan 1993, p. 62-63).

If we mean nothing more by qualia than this, then, pace Dennett, we can accept that there are qualitatively distinguishable ways that things appear to us without thereby committing ourselves to a dualistic ontology. The theoretically innocent approach I have been advocating, which avoids the errors to which Chalmers inclines and against which Dennett over-reacts, usefully clarifies the kind of the data we are seeking to understand - without committing us to philosophically corrupt accounts of it from the outset. 
DANIEL D. HUTTO

\section{Starting over}

From this vantage point, we can see that the debate between Chalmers and Dennett over whether we ought to prefer first-person or third-person approaches to the study of consciousness is wrong-headed and limited. We must recast our understanding of consciousness by recognising that we can only begin to approach it from within an interpretative, inter-subjective framework. That is to say, we must begin by seeing it in 'second personal' terms. As Olafson observes:

The importance of the decision one makes about where an inquiry is to begin can hardly be overestimated. That decision sets the character of its questions to be addressed; and by laying down the terms in which they are formulated, it can even carry an implicit commitment to a certain kind of answer to those questions (Olafson 1995, p. 16.).

If we start by reminding ourselves of the contexts, role and point of our utterances and expressions concerning experience, we will not be inclined to think of experiences as 'inner objects' or 'properties' in their own right - which might then have specifiable locations or which can be identified with or explained in terms of brain states or properties. Following James, we should adopt a more, "concrete way of seeing" (James 1909, p. 216). By ceasing to think of experiences abstractly, say as posits or theoretical constructs understood in vacuo, the temptation to reify or employ the 'object-based' schema is undercut. Instead of talking of distinct qualities such as 'redness' or 'softness', we will speak, as we ordinarily do, of our seeing something red (which in normal cases will be part of a much more complex visual scene) or being tickled by something soft. By attending to these contexts of action (acting and being acted upon), it is clear that 'having experiences' involves extended temporal activity and that experiencers are whole creatures or persons, not inner subjects. This is enough to turn many traditional problems, including the hard metaphysical problem and problems of other minds, on their heads.

This is not to deny that there are first-personal aspects to experience. It is rather to maintain that we can only get at these in a meaningful way via an intersubjective route. Although we have individual experiences, there is no such thing as first personal reports concerning them. Our capacity to give conceptual expression to our experience is late developing and likely, to some extent, to be transformative of our experience. Moreover, reference to 'experiences', or more perspicuously, the way we experience things, is anchored to descriptions of or about the character of public objects and events - or, in cases where there are nonesuch, what we take to be public objects and events. In this way, we work backwards in order to understand our first-personal responses.

Nor should adopting this line cause us to deny that some aspects of 
consciousness can only be investigated third personally. We should not doubt the prospects of future scientific work yielding, for example, more and more detail about the specific mechanisms that underpin certain types of experiences, as, for example, in the study of different sense modalities and their links to other brain and nervous systems. Knowledge of this kind will surely permit greater control, prediction and manipulation of experiences. Such developments will rightly be regarded as constituting an increase in our understanding of experiences. However, they will only tell us more about its causes; they could never give us a neutral insight in the nature or character of 'what it is like' to be an experiencer per se. We are reminded again that we have no choice but to begin our inquiries from an intersubjectively conditioned starting point; otherwise we will have no grip on the 'data' we are hoping to 'explain'. This is our ground. Thus even in studying experience third-personally, we must work forward from here.

\section{Notes}

1. I am grateful to the Mind Association for providing me with a Research Fellowship in 2004 that gave me the time to finalise this paper. Many of the views expressed in it have been influenced by comments and discussions that took place at the following conferences where earlier versions or aspects of ideas within were presented: Enactive Perception Symposium, organised by Centre for Research in Cognitive Science, Sussex and the Consciousness and Experimental section of the British Psychological Society, March 2004; Eastern Division Meeting of the American Philosophical Association, Washington, DC., December 2003; Embodiment and Intersubjectivity, Leuven, Belgium, September 2003; Towards a Science of Consciousness: Between Phenomenology and Neuroscience, Prague, July 2003; Towards a Science of Consciousness Conference, Skovde, Sweden, August 2001.

2. It is interesting, in this regard, that although they openly endorse much of Dennett's approach, O'Regan and Noë deviate from it by allowing that first-person reflection can play a role in investigations of experience. In particular they hold that "first-person reflection on the character of experience would not consist of introspection at all, but rather in attentiveness to the complexity of the activity of perceptual exploration" (O'Regan and Noë 2001, p. 965). I agree with the general spirit of this idea and even the thought that one would be focusing on the first-person aspects of experience in such cases; but the investigation would always need to be framed using concepts obtained in second-personal contexts.

\section{References}

Bickle, J. 1998. Psychoneural Reduction: The New Wave. Cambridge: MIT Press. Brandom, R. 1994. Making It Explicit. Cambridge, MA: Harvard University Press. Chalmers, D. 2003. The Content and Epistemology of Phenomenal Belief. In: Q. Smith and A. Jokic (eds.), Consciousness: New Philosophical Perspectives. Oxford: Oxford University Press. 
DANIEL D. HUTTO

Chalmers, D. 1999. First-Person Methods in the Science of Consciousness. Consciousness Bulletin from the Center for Consciousness Studies.

Churchland, P. M. 1989. A Neurocomputational Perspective: The Nature of Mind and the Structure of Science. Cambridge, MA: MIT Press.

Churchland, P. S. 1986. Neurophilosophy: Toward a Unified Science of the Mind-Brain. Cambridge, MA: MIT Press.

Crick, F. 1994. The Astonishing Hypothesis: The Scientific Search for the Soul. New York: Simon and Schuster.

Dennett, D. C. 1991. Consciousness Explained. New York: Penguin Books.

Dennett, D. C. 2002. How Could I Be Wrong? How Wrong Could I Be? Journal of Consciousness Studies 9(5-6): 13-16.

Dennett, D. C. 2003. Who's On First? Heterophenomenology Explained. Journal of Consciousness Studies 10(9-10): 19-30.

Dretske, F. 1995. Naturalizing the Mind. Cambridge, MA: MIT Press.

Find, A. 2001. Qualia Realism. Philosophical Studies 104(2): 143-162.

Flanagan, O. 1993. Consciousness Reconsidered. Cambridge, MA: MIT Press.

Humphrey, N. 2000. How to Solve the Mind-Body Problem. Journal of Consciousness Studies 7(4): 5-20.

Hutto, D. 1995. Consciousness Demystified: A Wittgensteinian Critique of Dennett's Project. The Monist 78(4): 464-479.

Hutto, D. 2000. Beyond Physicalism. Amsterdam: John Benjamins.

Hutto, D. 2003. Wittgenstein and the End of Philosophy: Neither Theory nor Therapy. Basingstoke: Palgrave Macmillan.

Hutto, D. 2006a. Unprincipled Engagements: Emotional Experience, Expression and Response. Consciousness and Emotion 7(1).

Hutto, D. 2006b. Knowing what? Radical versus conservative enactivism. Phenomenology and the Cognitive Sciences 7(1).

James, W. 1909. The Meaning of Truth. London: Longmans, Green and Co.

Lycan, W. 1996. Consciousness and Experience. Cambridge, MA: MIT Press.

Olafson, F. 1995. What Is a Human Being? A Heideggerian View. Cambridge: Cambridge University Press.

O'Regan, J. K. and Noë, A. 2001. A Sensorimotor Account of Vision and Visual Consciousness. Behavioural and Brain Sciences 24: 939-1031.

Penrose, R. 1994. Shadows of the Mind. Oxford: Oxford University Press.

Tye, M. 1996. Ten Problems of Consciousness: A Representational Theory of the Phenomenal Mind. Cambridge, MA: MIT Press.

Van Gulick, R. 2000. Closing the gap? Journal of Consciousness Studies 7(4): 93-97. 